\title{
VERIFYING THE WEIGHT OF DIFFERENT LEARNING TASKS IN STUDENT ASSESSMENT BY CHEMISTRY TEACHERS
}

\author{
WERYFIKACJA WAGI RÓŻNYCH ZADAŃ NAUKOWYCH \\ PRZEZ NAUCZYCIELI CHEMII POPRZEZ ANALIZE OCEN STUDENTÓW
}

\begin{abstract}
Learning tasks are a great motivation tool in chemistry teaching, necessary in the exposure and fixation part of a teaching process, and also often used when diagnosing the depth and type of student knowledge. Our research analysed the relationship between the student assessment in chemistry and their success in solving memory, algorithmic and conceptual tasks at symbolic, submicroscopic and macroscopic levels. The testing focused on chemical equilibrium, because this topic is appropriate to design and test the tasks. The collected data was evaluated by one-factor ANOVA analysis. We expected that, in comparison to average and weak learners, the excellent ones should be significantly more successful in tackling all the types of tasks and at all levels. However, our findings indicate that this assumption is invalid in the case of conceptual tasks, i.e. the understanding the depth of chemical concepts does not always correlate with the student assessment.
\end{abstract}

Keywords: chemical equilibrium, learning task, student assessment

\section{Introduction}

The school performance of students based on school assessment provides an important feedback both towards the students and teachers. At the same time, it can be perceived as an important regulatory tool leading to the preference of certain objectives in acquiring the student knowledge and competences in the educational process. The formation of the school assessment lies in the level of solving the situations (learning tasks) induced by a teacher in the class. The structure of learning tasks and the weight that teachers assign to them is determined by the feedback and the preference of learning objectives.

We consider examining the relationship between school assessment and the success of students in solving learning tasks a very significant role of didactics. We have been dealing a lot with such types of research and therefore, we would like to provide some of our results. From the chemical content point of view, our research focused on the chemical equilibrium. From a didactic point of view, the research investigated the relationship between the assessment of students in chemistry and their success in solving memory,

\footnotetext{
${ }^{1}$ Department of Didactics in Science, Psychology and Pedagogy, Faculty of Natural Sciences, Comenius University in Bratislava, Mlynská dolina, Ilkovičova 6, 84215 Bratislava, Slovak Republik, phone +421260296311

*Corresponding author: zuzana.halakova@uniba.sk
} 
algorithmic, conceptual tasks at submicroscopic, macroscopic and symbolic representations of chemical equilibrium.

\section{Prior research}

Learning tasks are a powerful tool of teachers in the pursuit of cognitive development of students. The character, content and form of the assignments are factors that decide on the deepening the student knowledge or only on superficial knowledge of the facts. Johnstone [1] considers three factors related to the assigned task: the collected data, the used methods and the objective to be achieved. While respecting and considering Bloom taxonomy of cognitive goals or its revised version [2], the tasks can be assigned to students based on the different levels of mastering a specific concept or content ranging from the simplest and least difficult remembering through understanding, application, analysis, synthesis to evaluation. The categories of cognitive processes comprise factual information, conceptual knowledge, procedural knowledge and metacognitive strategies at the highest level.

Bloom's taxonomy and its revised version is not the only classification that can be used in our research. Other taxonomies or selected types of tasks are also used in the research work. We list some of them related to the research carried out in this field below.

Open questions are used to establish the depth of understanding and the level of associations with the selected concept and/or phenomenon. They can provide a variety of correct solutions and a wide range of suitable methods for solving such tasks [3]. They are variable, reflect real situations, and require students to grasp the concept in the everyday life context.

To identify the level of higher order thinking skills in students [4], i.e. conceptually thinking students, Nakhleh [5] used a 5-item pair test including five topics of general chemistry (gas laws, chemical equations, determined reactant, formulae, density). One set comprised one algorithmic and one conceptual task. A similar tool was used by Papaphotis and Tsaparlis [6]. Two-level [7], three-level [8] or even four-level [9] tests are used to establish the level of conceptual understanding.

The advantage of using tests with multiple choice tasks lies in requiring specific facts and concepts from students. Computational test items entail the ability to transform information in various ways while problem-solving, i.e. justification at the formal operational level $[10,11]$.

As early as in the 1990s, the research suggested that students were able to solve problems numerically when related to the understanding of a specific concept, but they encountered problems when solving the same problem examining its conceptual understanding $[5,11]$.

Surif et al. [12] pointed out that students' success in solving algorithmic tasks in chemistry reaches $96 \%$, while conceptual $54 \%$ and open $15 \%$. Papaphotis and Tsaparlis [6] achieved even more alarming results and found that if students are able to solve algorithmic tasks, it does not mean that they can also deal with the conceptual ones. Both Chiu [13] and Cracolice et al. [7] confirmed that students have a higher level of algorithmic abilities compared to the conceptual ones.

Algorithmic tasks are useful in solving common questions and assignments, but also in following a set of instructions to get a solution through calculation [14]. In this type of solutions, the students are usually aware of all the information and its incorporation into 
a mathematical model, tool, formula and then, the goal is relatively easily achieved $[1,3]$. This involves the application of knowledge in a usual and standard way [12]. Therefore, algorithm problem is often just a practice, training and is part of the textbook assignments [1]. Frank et al. [15] claimed that students, in fact, do not solve the problem in this way, they only search for and select an algorithm they could use in the given situation. However, this is to their disadvantage and even restricts them to solve the conceptual problems successfully [12].

Yavuz Mumcu and Yildiz [16] pointed out that a student with an algorithmic way of thinking tends to grasp the problem only theoretically using a mathematical apparatus, coding. However, the algorithmic approach is considered to be part of so-called computer thinking that includes creative and critical thinking, problem solving, cooperative learning and communicational skills. Niaz and Robinson [11] stated that it is the developmental level/stage of an individual that predicts the success in solving algorithmic task.

Conceptual tasks force students to merge, synthesise, and reassess responses, are based on understanding, not automation and routine procedures. They relate to the observed phenomena and assume insights into the chemical nature of the phenomenon explained by students correctly [12]. Nurrenbern and Pickering [17] presented several types of conceptual tasks: multi-level with multiple-choice, with a particle visualisation (including microscopic or symbolic representation), laboratory (data interpretation in a graph, table), demonstration tasks (observing the phenomenon at the macroscopic level), analogy tasks, sets of complementary tasks. Surif et al. [12], Nuzulia, Hasan and Ismayani [18] also used this categorisation. However, Niaz [19] asserts that if students can manage the conceptual tasks, they can successfully solve also the algorithmic ones.

In their research, Yavuz Mumcu and Yildiz [16] reported the highest success in solving algorithmic tasks and the lowest in solving logical tasks (tracing tasks and the tasks requiring analysis were also part of the test).

Niaz and Robinson [11] found out that the ability to solve computational tasks does not predict the success in solving conceptual problems. Solving problems based on the use of algorithmic strategies assumes a certain level of formal operations. Moreover, the student's ability to successfully solve problems requiring conceptual understanding relates to various cognitive variables such as a level of development, mental capacity, or cognitive style.

Nurrenbern and Pickering [17] pointed out that nearly two-thirds of students are able to successfully solve chemical computational problems related to gas laws, but only one-third conceptually. Sawrey [20] achieved similar results in stoichiometry.

Nuzulia, Hasan and Ismayani [18] claim that the interconnection of macroscopic, symbolic, and microscopic levels of concept and phenomenon representation may lead to enhancing the conceptual understanding of chemical concepts by students. Research results by Herron, Nurrenbern [21] and Johnstone [22] have already indicated that students encounter problems when interconnecting symbolic, macroscopic and microscopic levels of chemical phenomenon representation. Surif et al. [12] asserted that students cannot comprehend all three levels in chemistry at once. The submicroscopic understanding or visual representation of a chemical reaction or concept seemed to be the most difficult for students [5,23], and therefore, the majority of misconceptions were reported mainly at this level [12].

Calyk et al. [24] pointed out to several problems in understanding chemical concepts in their review study. These include, for instance, a lack of justification for the macroscopic 
observation of the phenomenon at the submicroscopic level, the difficulty of visualising and representation of the submicroscopic nature, or a symbolic representation.

Our aim was to link these two aspects, i.e. approach to different types of assignments in chemistry and representation of chemical equilibrium at various levels; and to find connections between the success of students in solving different chemical learning tasks and their assessment in chemistry.

\section{Aims and objectives}

In our research, we focused on the connection of school assessment of chemistry students and their success in solving individual types of learning tasks. We consider this interesting because, to some extent, it can indicate how teachers apply the results of solving such learning tasks by students in the assessment of their school performance.

The research question can be formulated as follows: Do teachers use memory, algorithmic, conceptual tasks and the tasks with macroscopic, submicroscopic and symbolic representation in the assessment of students' performance with equal weight?

\section{Methodology of research}

The research tool consisted of five sets of tasks with 15 subtasks altogether. Since all the subtasks of one particular set were based on the common problem identified in the assignment, we obtained a more concentrated comprehension of how students understand the key aspects of the chemical equilibrium. The researched topics included the understanding of the reverse reaction, the equilibrium constant and the effect of temperature, pressure and concentration change on the stabilisation of the new equilibrium.

Individual tasks formed three groups of tasks - a group of memory reproduction tasks, a group of tasks focused on the algorithmic level and a group of tasks reflecting the conceptual understanding of selected nodes related to chemical equilibrium. From another point of view, the questions were categorised as those with macroscopic, submicroscopic and symbolic representation.

Our research tool was presented at the 2nd International Baltic Symposium on Science and Technology Education in Siauliai, Lithuania in June 2017 [25] and described in detail in Learners' Understanding of Chemical Equilibrium at Submicroscopic, Macroscopic and Symbolic Levels [26]. For this reason, we are not going to discuss the specific assignment of learning tasks of the research tool in this study.

The research was carried out in 2017 and employed 473 secondary school students aged 16 and over. The students were from 15 different teachers and 22 classes in eight Slovak schools. The research sample can be indicated as an available population selection.

\section{Results and discussion}

In our research a one-factor ANOVA analysis was chosen for a deeper understanding of the relationship between the school assessment of chemistry students and the success of solving different types of learning tasks. We established the assessment in chemistry as the investigated factor of three levels - excellent, average and weak students. In order to classify the tasks, we chose the attribute of the predominant characteristic of a student's activity which leads to the task solution, i.e. the prevailing application of memory reproduction, algorithm or conceptual mastery of the given topic. The second attribute was 
the level of interpretation of the chemical phenomena dealt with in the tasks. According to the latter attribute we distinguished groups with tasks of symbolic, macroscopic and submicroscopic interpretation.

We assumed that there should be the difference in the success of the solutions in the tasks of our research test according to the investigated factor. Thus, a group of excellent students (mark 1 according to the school assessment) will be significantly better than a group of average students (mark 2). Similarly, the group of average students will be significantly better than the group of weak students (mark 3 or worse). At the same time, we also expected that the excellent students would be more successful than the weak students. Such postulates are expected in all types of tasks, i.e. memory, algorithmic and conceptual tasks, as well as those with macroscopic, submicroscopic and symbolic interpretation.

Our initial postulate can also be formulated as follows: the characteristics, according to which teachers distinguished the students as excellent, average and weak, are identical with those that presume the success of students in the research test tasks.

If there are other relationships reported in the experimental data, the characteristics conducive to the assessment categorisation are not identical with those assuming the successful solution of each type of the test tasks.

In order to interpret the collected data, we had to process and make it transparent first. Table 1 displays the average relative success rate of students with respect to a possible point gain in each task group for the selected groups of students.

Table 1

The average relative success rate of student groups in solving the different task types

\begin{tabular}{|c|c|c|c|c|c|c|c|c|c|c|c|c|}
\hline \multirow{3}{*}{$\begin{array}{l}\text { Success } \\
\text { rate of } \\
\text { chemistry } \\
\text { students }\end{array}$} & \multicolumn{12}{|c|}{ Average relative success rate of student groups in solving the different task types } \\
\hline & \multicolumn{2}{|c|}{ Memory } & \multicolumn{2}{|c|}{ Algorithmic } & \multicolumn{2}{|c|}{ Conceptual } & \multicolumn{2}{|c|}{$\begin{array}{c}\text { Symbolic } \\
\text { interpretation }\end{array}$} & \multicolumn{2}{|c|}{$\begin{array}{l}\text { Macroscopic } \\
\text { interpretation }\end{array}$} & \multicolumn{2}{|c|}{\begin{tabular}{|c|} 
Submicro- \\
scopic \\
interpretation
\end{tabular}} \\
\hline & $\overline{\boldsymbol{x}}$ & Variance & $\overline{\boldsymbol{x}}$ & Variance & $\overline{\boldsymbol{x}}$ & Variance & $\overline{\boldsymbol{x}}$ & Variance & $\overline{\boldsymbol{x}}$ & Variance & $\bar{x}$ & Variance \\
\hline $\begin{array}{c}\text { Excellent } \\
\text { students }\end{array}$ & 0.583 & 0.014 & 0.388 & 0.020 & 0.529 & 0.013 & 0.519 & 0.016 & 0.110 & 0.020 & 0.700 & 0.015 \\
\hline $\begin{array}{l}\text { Average } \\
\text { students }\end{array}$ & 0.546 & 0.012 & 0.356 & 0.017 & 0.499 & 0.011 & 0.478 & 0.010 & 0.076 & 0.013 & 0.678 & 0.013 \\
\hline $\begin{array}{c}\text { Weak } \\
\text { students }\end{array}$ & 0.494 & 0.012 & 0.285 & 0.012 & 0.479 & 0.007 & 0.416 & 0.010 & 0.028 & 0.006 & 0.639 & 0.012 \\
\hline
\end{tabular}

As we can see in Table 1, the memory reproduction tasks were managed best by the students in our research, followed by the conceptual tasks and the algorithmic ones rated as worst. From the second attribute point of view, the solutions of the tasks focused on the submicroscopic level of chemical equilibrium representation were rated as most successful, followed by the symbolic level tasks. The respondents were least successful in solving the tasks with macroscopic representation.

We verified the normality of distribution for individual groups of students in the next step of the results processing. We used the d'Agostino-Pearson normality test. The results show that the normality of the distribution is maintained in the observed groups. This result helped us select the statistical means of further data processing.

We chose a one-factor analysis for further processing of the research data. Firstly, we wanted to establish the statistical significance of the variance differences. We applied the second step of the one-factor ANOVA in the cases with statistically significant differences 
in variance. Using the Tukey HSD test, we determined the statistical significance of the variation in students' average performance in all relevant combinations (Tables 2-9).

Table 2

One-factor analysis in solving memory, algorithmic and conceptual tasks

\begin{tabular}{|c|c|c|c|c|c|c|}
\hline Variables & \multicolumn{2}{|c|}{ Memory } & \multicolumn{2}{c|}{ Algorithmic } & \multicolumn{2}{c|}{ Conceptual } \\
\hline & $\boldsymbol{F}$ & $\boldsymbol{p}$ & $\boldsymbol{F}$ & $\boldsymbol{p}$ & $\boldsymbol{F}$ & $\boldsymbol{p}$ \\
\hline Mark & 13.228 & $0.000003^{*}$ & 14.353 & 0.000001 & 5.131 & 0.006544 \\
\hline
\end{tabular}

$F$ - value of Tukey HSD test; $p$ - probability value

"red colour font is used in cases the difference of results is statistically significant

Table 3

One-factor analysis for symbolic, macroscopic and submicroscopic interpretation tasks

\begin{tabular}{|c|c|c|c|c|c|c|}
\hline Variables & \multicolumn{2}{|c|}{$\begin{array}{c}\text { Symbolic } \\
\text { interpretation }\end{array}$} & \multicolumn{2}{c|}{$\begin{array}{c}\text { Macroscopic } \\
\text { interpretation }\end{array}$} & \multicolumn{2}{c|}{$\begin{array}{c}\text { Submicroscopic } \\
\text { interpretation }\end{array}$} \\
\hline & $\boldsymbol{F}$ & $\boldsymbol{p}$ & $\boldsymbol{F}$ & $\boldsymbol{p}$ & $\boldsymbol{F}$ & $\boldsymbol{p}$ \\
\hline Mark & 18.702 & 0.000000 & 11.1718 & 0.000022 & 5.958 & 0.002963 \\
\hline
\end{tabular}

Our assumption about the conformity of the characteristics, according to which teachers distinguished students as excellent, average and weak, and those conducive to students' success in the above-mentioned task types, was fully confirmed only in the tasks with symbolic interpretation of the observed phenomena (Table 4).

Table 4

Tukey HSD test - symbolic interpretation

\begin{tabular}{|c|c|c|c|}
\hline Mark & Excellent students & Average students & Weak students \\
\hline Excellent students & & 0.041698 & 0.000022 \\
\hline Average students & 0.041698 & & 0.000753 \\
\hline Weak students & 0.000022 & 0.000753 & \\
\hline
\end{tabular}

Table 5

Tukey HSD test - memory tasks

\begin{tabular}{|c|c|c|c|}
\hline Mark & Excellent students & Average students & Weak students \\
\hline Excellent students & & 0.085505 & 0.000022 \\
\hline Average students & 0.085505 & & 0.007685 \\
\hline Weak students & 0.000022 & 0.007685 & \\
\hline
\end{tabular}

Table 6

Tukey HSD Test - algorithmic tasks

\begin{tabular}{|c|c|c|c|}
\hline Mark & Excellent students & Average students & Weak students \\
\hline Excellent students & & 0.232716 & 0.000022 \\
\hline Average students & 0.232716 & & 0.000924 \\
\hline Weak students & 0.000022 & 0.000924 & \\
\hline
\end{tabular}

Certain deviations can be observed in other task types. We found out that the school assessment does not predict the student success in the tasks with memory, algorithmic and macroscopic interpretation for a group of excellent and average students (Tables 5, 6 and 7). This indicates that chemistry teachers do not include all the characteristics conducive to 
the success in the assessment of excellent and average students when solving these types of tasks, i.e. the tasks are not assigned the same weight.

Tukey HSD test - macroscopic interpretation

\begin{tabular}{|c|c|c|c|}
\hline Mark & Excellent students & Average students & Weak students \\
\hline Excellent students & & 0.129948 & 0.000029 \\
\hline Average students & 0.129948 & & 0.015455 \\
\hline Weak students & 0.000029 & 0.015455 & \\
\hline
\end{tabular}

The greatest deviations in our initial assumptions and the measured data are observed in the conceptual tasks and in the tasks with submicroscopic interpretation of the chemical phenomena (Tables 8 and 9). Only the difference in the success of solving these types of tasks between the groups of excellent and weak learners is in accordance with our postulates. In other cases, the mark in chemistry does not predict the success in the task solving.

Tukey HSD test - conceptual tasks

\begin{tabular}{|c|c|c|c|}
\hline Mark & Excellent students & Average students & Weak students \\
\hline Excellent students & & 0.146055 & 0.004114 \\
\hline Average students & 0.146055 & & 0.388286 \\
\hline Weak students & 0.004114 & 0.388286 & \\
\hline
\end{tabular}

Tukey HSD test - submicroscopic interpretation

\begin{tabular}{|c|c|c|c|}
\hline Mark & Excellent students & Average students & Weak students \\
\hline Excellent students & & 0.420357 & 0.001871 \\
\hline Average students & 0.420357 & & 0.078805 \\
\hline Weak students & 0.001871 & 0.078805 & \\
\hline
\end{tabular}

If we investigate our findings in detail, we can state that they concern the tasks that should reflect the deepest understanding of chemical phenomena, i.e. the conceptual mastering and interpretation of chemical phenomena at submicroscopic level. Therefore, we can assume that the student assessment by teachers does not sufficiently include exactly the most important attributes. On the other hand, the complete agreement between the marks and the measured performance of students in selected groups in the symbolic interpretation tasks suggests that chemical nomenclature, symbols, formulae and chemical equations are still considered a very important part of the chemistry assessment and the weight the teachers attribute to them.

\section{Conclusion}

We consider our results and their interpretation valid for our research tool and research sample of Slovak students and teachers. We have no ambition to generalise the results to the entire population and to all learning tasks in chemistry. Nevertheless, we believe that the findings can serve as a pilot research both in terms of the methodology applied in the research, and in terms of the results and subsequent conclusions. 
A further research should focus on the enlargement of the research sample of students taught by a larger number of different teachers from a number of different schools. We endeavour to achieve at least a representative sample of students and chemistry teachers in Slovakia. We will also strive to extend the content of learning tasks to other key areas of chemistry, not just the chemical equilibrium.

We hope that our research, the aim and objectives, methodology and presented results will inspire other researchers in the area. It would be possible to minimise the impact of the availability of the research sample and provide a more complex generalisation of the results if there were more studies on this topic. In addition, it would also open room for comparison of the studied topic in different countries or didactic systems with different aims, organisation, teaching methods and tools applied in the educational process.

\section{References}

[1] Johnstone AH. Introduction. In: Wood C, Sleet R, editors. Creative Problem Solving in Chemistry. London: The Royal Society of Chemistry; 1993. ISBN: 9781870343282.

[2] Anderson LW, Krathwohl DR, Airasian PW, Cruikshank KA, Mayer RE, Pintrich PR, et al. A Taxonomy for Learning Teaching and Assessing: A Revision of Bloom's Taxonomy of Educational Objectives (complete edition). New York: Longman; 2001. ISBN: 9780321084057.

[3] Reid N, Yang MJ. The solving of problems in chemistry: the more open-ended problems. Res Sci Tech Educ. 2002;20(1):83-98. DOI: 10.1080/02635140220130948.

[4] Tobias S. They're not Dumb. They're Different: Stalking the Second Tier. Research Corporation: Tucson. AZ, 1994. ISBN: 9780963350404.

[5] Nakhleh MB. Are our students conceptual thinkers or algorithmic problem solvers? J Chem Educ. 1993;70(1):52-5. DOI: 10.1021/ed070p52.

[6] Papaphotis G, Tsaparlis G. Conceptual versus algorithmic learning in high school chemistry: The case of basic quantum chemical concept. Chem Educ Res Pract. 2008; 9(4):332-40. DOI: 10.1039/b818468m.

[7] Cracolice MS, Deming JC, Ehlert B. Concept learning versus problem solving: A cognitive difference. J Chem Educ. 2008;85(6):873-8. DOI: 10.1021/ed085p873.

[8] Cetin-Dindar A, Omer Geban O. Development of a three-tier test to assess high school students' understanding of acids and bases. Proc Soc Behav Sci. 2011;15:600-4. DOI: 10.1016/j.sbspro.2011.03.147.

[9] Habiddin H, Page EM. Development and validation of a four-tier diagnostic instrument for chemical kinetics (FTDICK). Indones J Chem. 2019;19:720-36. DOI: 10.22146/ijc.39218.

[10] Lawson AE. Predicting science achievement: The role of developmental level, disembedding ability, mental capacity, prior knowledge and beliefs. J Res Sci Teach. 1983;20(2):117-29. DOI: 10.1002/tea.3660200204.

[11] Niaz M, Robinson WR. Teaching algorithmic problem solving or conceptual understanding: Role of developmental level. mental capacity and cognitive style. J Sci Educ Technol. 1993;2(2):407-16. DOI: 10.1007/bf00694529.

[12] Surif J, Ibrahim NH, Dalim SF. Problem solving: algorithms and conceptual and open-ended problems in chemistry. In: 5th World Conference on Educational Sciences. Book Series: Proc Soc Behav Sci. Amsterdam: Elsevier. 2014;116:4955-63. DOI: 10.1016/j.sbspro.2014.01.1055.

[13] Chiu MH. Algorithmic problem solving and conceptual understanding of chemistry by students at a local high school in Taiwan. Proc Natl Sci Counc. 2001;11(1):20-38. Available from: https://ejournal.stpi.narl.org.tw/index/items/download?viId=A384FBF4-F44C-47DD-A8D45353BAEE1490.

[14] Bodner GM. The role of algorithms in teaching problem solving. J Chem Educ. 1987;64(6):513-4. DOI: 10.1021/ed064p513.

[15] Frank DV, Baker CA, Herron JD. Should students always use algorithms to solve problems? J Chem Educ. 1987;64(6):514-5. DOI: 10.1021/ed064p514.

[16] Yavuz Mumcu H, Suheda Yildiz S. The investigation of algorithmic thinking skills of fifth and sixth marks at a theoretical dimension. J Math Educ. 2018;3(1):41-8. Available from: https://pdfs.semanticscholar.org/1475/c3401d083b2e0b5a85637500b023300fdc12.pdf.

[17] Nurrenbern SA, Pickering M. Concept learning versus problem solving: is there a difference? J Chem Educ. 1987;64(6):508. DOI: 10.1021/ed064p508.

[18] Nuzulia, Hasan M, Ismayani A. Assessing conceptual and algorithmic understanding of students in senior high school. J Phys. Conf Series. 2018; 1088.012092. DOI: 10.1088/1742-6596/1088/1/012092. 
[19] Niaz M. Relationship between student performance on conceptual and computational problems of chemical equilibrium. Int J Sci Educ. 1995;17(3):343-55. DOI: 10.1080/0950069950170306.

[20] Sawrey BA. Concept learning versus problem solving: Revisited. J Chem Educ. 1990;67(3):253. DOI: 10.1021/ed067p253.

[21] Herron JD, Nurrenbern SA. Chemical education research: Improving chemistry learning. J Chem Educ. 1999;76(10):1354-61. DOI: 10.1021/ed076p1353.

[22] Johnstone AH. Why is science difficult to learn? Things are seldom what they seem. J Comp Assist Learning. 1991;7(2):75-83. DOI: 10.1111/j.1365-2729.1991.tb00230.x.

[23] Garnett PJ, Hacking MW. Students' alternative conceptions in chemistry: a review of research and implications for teaching and learning. Stud Sci Educ. 1995;25(1):69-95. DOI: $10.1080 / 03057269508560050$.

[24] Calyk M, Ayas A, Ebenezer JV. A review of solution chemistry studies: Insights into students' conceptions. J Sci Educ Technol. 2005;14:29-50. DOI: 10.1007/s10956-005-2732-3.

[25] Prokša M, Haláková Z, Drozdíková A. Chemical equilibrium in terms of its conceptual understanding in the context of submicroscopic, macroscopic and symbolic interpretation by learners. Science and Technology Education: Engaging the New Generation. Proc 2nd Int Baltic Symp Sci Technol Educ (BalticSTE 2017). Siauliai: Scientia Socialis. 2017; 104-7. ISBN: 9786099551340.

[26] Prokša M, Drozdíková A, Haláková Z. Learners’ understanding of chemical equilibrium at submicroscopic, macroscopic and symbolic levels. Chem Didact Ecol Metrol. 2018;23(1-2):97-111. DOI: 10.1515/cdem-2018-0006. 